\title{
Current Status of Acute Rheumatic Fever and Relationship with Acute Rheumatic Heart Disease at the University Teaching Hospital of Brazzaville (Congo)
}

\author{
Bertrand Fikahem Ellenga Mbolla1, Gaston Ekouya-Bowassa ${ }^{1,2}$, Pierre Poathy ${ }^{2}$, Moyen Engoba ${ }^{1,2}$, \\ Annie Rachel Okoko',2, Aurore Mbika-Cardorelle1,2, Suzy-Gisèle Kimbally-Kaky \\ ${ }^{1}$ Department of Doctotal Studies, Faculty of Health Sciences, Marien Ngouabi University, Brazzaville, Congo \\ ${ }^{2}$ Department of Pediatrics, University Teaching Hospital of Brazzaville, Brazzaville, Congo \\ Email: ellenga_bertrand@hotmail.com
}

How to cite this paper: Mbolla, B.F.E., Ekouya-Bowassa, G., Poathy, P., Engoba, M., Okoko, A.R., Mbika-Cardorelle, A. and Kimbally-Kaky, S.-G. (2019) Current Status of Acute Rheumatic Fever and Relationship with Acute Rheumatic Heart Disease at the University Teaching Hospital of Brazzaville (Congo). World Journal of Cardiovascular Diseases, 9, 812-819.

https://doi.org/10.4236/wjcd.2019.911072

Received: October 9, 2019

Accepted: November 17, 2019

Published: November 20, 2019

Copyright $\odot 2019$ by author(s) and Scientific Research Publishing Inc. This work is licensed under the Creative Commons Attribution International License (CC BY 4.0).

http://creativecommons.org/licenses/by/4.0/ (c) (i) Open Access

\begin{abstract}
Aim: To determine the epidemiological findings of acute rheumatic fever (ARF) and relationship with acute rheumatic heart disease (RHD). Patients and method: This cross sectional study was conducted from January 2012 to December 2016 (5 years) in the Department of Pediatrics. We had included patients aged from 5 to15 years old, admitted for ARF. Results: Twenty-nine black African children, 15 boys (51.7\%) were included. The incidence was 5.8 cases/year. The mean age was $10.4 \pm 2.7$ years. The mean age of parents was $34.5 \pm 6.9$ years (range: $24-48$ ) for mother and $41.2 \pm 6.9$ years (range: 28 56) for father. Parents were low-income $10(34.5 \%)$, the delay of consultation was $17.7 \pm 19.5$ days. The medical history was: frequent pharyngitis $22(76 \%)$, previous ARF 17 (58.6\%), previous hospitalization 11 (38\%). Signs were: polyarthralgia $(n=28,96.6 \%)$, fever $(n=24,82.8 \%)$, asthenia $(n=18,62 \%)$, migratory polyarthritis $(\mathrm{n}=12,41.4 \%)$. Organic heart murmur has been reported in 13 cases (44.8\%), and heart failure in 7 cases. The anomalies of blood analysis were inflammatory syndrome $(100 \%)$, elevation of streptococcal enzymes $(n=27,93 \%)$, and anemia $(n=16,55.2 \%)$. In cardiac ultrasound, anomalies were: thickened valve $(\mathrm{n}=13,44.8 \%)$, mitral regurgitation $(\mathrm{n}=13,44.8 \%)$, dilatation of left ventricle $(\mathrm{n}=9,31 \%)$, aortic regurgitation ( $\mathrm{n}=5,17.2 \%)$. The nosology of pathology was acute RHD $(\mathrm{n}=15,51.7 \%)$, ARF only $(\mathrm{n}=14,48.3 \%)$. Associated factors of acute RHD were: female sex (OR 1.52, 95\%CI 0.35 - 6.6), low-income (OR 1.33, 95\%CI 0.24 - 7.4), previous hospitalization (OR $2.7,95 \% \mathrm{CI} 0.58$ - 13) and migratory polyarthritis (OR 1.12, 95\%CI 0.25 - 4.9). Conclusion: The ARF remains prevalent in our countries. Its complications lead to sequelae that are difficult to treat, because
\end{abstract}


of the lack of cardiac surgery centers in many sub-Saharan African countries including Congo. Prevention and effective treatment of angina should be applied by practitioners.

\section{Keywords}

Acute Rheumatic Fever, Rheumatic Heart Disease, Infants, Black African, Sub-Saharan Africa

\section{Introduction}

Acute rheumatic fever (ARF) is an autoimmune condition secondary to infection with $B$-hemolytic streptococcus [1] [2]. The most common infection is pharyngitis, an effective treatment with inexpensive antibiotics [1]. ARF can cause acute heart disease (carditis) [1], thus defining the acute rheumatic heart disease (RHD), requiring specialized management [2] [3].

Repeated infections and poor management lead to rheumatic heart diseases (RHD), the treatment of which requires cardiac surgery [1] [4]. Les RHD remains a public health problem in low income countries [5] [6] [7]. They are currently considered a neglected tropical disease [8] [9]. Indeed, their incidence persists in low-income countries, and high mortality, while in high-income countries they are eradicated [5] [6] [8] [10]. In sub-Saharan Africa, their incidence varies across countries. Screening studies in schools showed frequencies of 2.3\% in Mozambique, and 3.5\% in Brazzaville [11] [12]. This prevalence is higher (30\%o), during echocardiography screening [12]. This high prevalence is related to adverse socio-economic conditions, and the limits of access to care, justify the deficiency of effective management of pharyngitis, and prevention with penicillin in subjects at risk [5] [13].

The severity of these diseases in sub-Saharan Africa is related to their occurrence, in a context of absence of cardiac surgery center in most countries [4] [14]. Calls to African leaders have been made for the complete eradication of these diseases in Africa [7]. It seemed useful to take stock of the current state of ARF and acute RHD among children admitted to the University Teaching Hospital of Brazzaville.

The aim of this study was to determine the epidemiological and clinical findings of ARF and relationship with acute RHD.

\section{Method}

This cross sectional study was conducted from January 2012 to December 2016 (5 years) in the department of pediatrics (unit of infants and adolescents) at the teaching university hospital of Brazzaville. Brazzaville is the biggest city of the republic of Congo, the population was 1.5 million [15]. Brazzaville is located in African tropical area. The Republic of the Congo is categorized as a low and 
moderate-income country by the World Bank, and the rate of severe poverty was $40.9 \%$ [15].

The department where the study was conducted, welcomes children aged 5 15 years old, for all pathologies. All children admitted for ARF during the period of study, were included. Adolescents admitted for RHD in hospital, without ARF were not included. The confidentiality of data, according the protocol of Helsinki 1975 was respect. The diagnosis of ARF and acute RHD was made according to Jones criteria [2]. Blood tests were carried out at the laboratory of medical biology of the University Hospital of Brazzaville. Study variables were epidemiological (age, gender, medical history, parents age, habitation), clinical (signs) and complementary examinations (blood analyses, chest X-ray, EKG, echocardiography).

\section{Definitions}

Inflammatory syndrome was defined by the elevation of erythrocyte sedimentation rate or the elevation of $\mathrm{C}$ reactive protein.

Low-income was defined as household income below the minimum salary in the Republic of Congo (US \$ 150), or income below US \$ 1.96 according to the World Bank [15].

Anemia was defined by haemoglobin less than $8 \mathrm{~g} / \mathrm{dL}$ for several form, and from 8 to 10.9 for moderate form [16].

Prolonged hospitalization was retained for the duration of hospitalization upper 3 weeks.

Statistical analysis. Data were processed by Excel Microsoft $\odot$ and analyzed by Epi Info3.3.2 @ (CDC Atlanta, USA) software. Qualitative variables were presented in number ( $\mathrm{n}$ ) and percentage (\%). Quantitative variables were presented on mean \pm standard deviation and range. The comparison of qualitative variables used the Chi-squared test. For the comparison of quantitative variables, the Student's t-test was used. An Odds-ratio (OR) calculation was performed with their $95 \%$ confidence interval (CI) to determine associated factors of acute RHD. The significance threshold for comparisons was $<5 \%$.

\section{Results}

Twenty-nine black African children, 15 boys (51.7\%) were included. Sex-ratio was 1.07. The incidence was 5.8 cases/year. The mean age was $10.4 \pm 2.7$ years old. The mean age of parents was $34.5 \pm 6.9$ years (range: $24-48$ ) mother and $41.2 \pm 6.9$ years (range: 28 - 56) father. The socio-demographics findings and the medical history of patients are reported in Table 1.

Signs were: polyarthralgia $(\mathrm{n}=28,96.6 \%)$, fever $(\mathrm{n}=24,82.8 \%)$, asthenia $(\mathrm{n}=$ $18,62 \%)$, migratory polyarthritis $(\mathrm{n}=12,41.4 \%)$, functional impotence of a limb $(\mathrm{n}=10,34.5 \%)$, dyspnea $(\mathrm{n}=7,21 \%)$, chest pain $(\mathrm{n}=4,13.8 \%)$, vomiting $(\mathrm{n}=$ $3,10.3 \%)$, cough $(\mathrm{n}=3)$, palpitations $(\mathrm{n}=1)$, skin lesions $(\mathrm{n}=1)$. In physical examination, the heart rate (beat $/ \mathrm{min}$ ) was $98.7 \pm 20$ (range: 58 - 136), weight was $(\mathrm{Kg}) 32.6 \pm 11$ (range: $18-68$ ), third heart sound was reported in 5 cases (17.2\%), hepatomegaly in 2 cases, and fluid retention syndrome in 1 case. 
Table 1. Epidemiology, medical history of patients, and nosology.

\begin{tabular}{|c|c|c|}
\hline & $\mathrm{n}$ or mean & $\%$ or range \\
\hline \multicolumn{3}{|l|}{ Epidemiology } \\
\hline Male sex & 15 & 51.7 \\
\hline Female sex & 14 & 48.3 \\
\hline Mother age (years) & $34.5 \pm 6.9$ & $24-48$ \\
\hline Father age (years) & $41.2 \pm 6.9$ & $28-56$ \\
\hline Divorced parents & 3 & 10.3 \\
\hline Siblings (children/family) & $4.4 \pm 1$ & $3-6$ \\
\hline Infants in room (children/room) & $3.2 \pm 0.4$ & $3-4$ \\
\hline Low-income & 10 & 34.5 \\
\hline Delay of consult (days) & $17.7 \pm 19.5$ & $4-90$ \\
\hline Disturbed schooling & 5 & 17.2 \\
\hline \multicolumn{3}{|l|}{ Medical history } \\
\hline Frequent pharyngitis & 22 & 76 \\
\hline Previous ARF & 17 & 58.6 \\
\hline Previous hospitalization & 11 & 38 \\
\hline Previous acute RHD & 6 & 20.7 \\
\hline RHD & 6 & 20.7 \\
\hline Medical prevention (penicillin) & 6 & 20.7 \\
\hline Drepanocytosis & 2 & 7 \\
\hline HIV & 1 & \\
\hline \multicolumn{3}{|l|}{ Nosology } \\
\hline Acute RHD & 15 & 51.7 \\
\hline ARF only & 14 & 48.3 \\
\hline Rheumatic recurrence & 7 & 24.1 \\
\hline Pancarditis & 2 & 7 \\
\hline
\end{tabular}

ARF: acute rheumatic fever. RHD: rheumatic heart disease. HIV: Human immunodeficiency virus.

Organic heart murmur has been reported in 13 cases (44.8\%), and heart failure in 7 cases. In blood analysis, hemoglobin rate $(\mathrm{g} / \mathrm{dL}$ ) was $10.6 \pm 2.3$ (range: 5.9 15.3), and white cell count (cell/ $\left./ \mathrm{mm}^{3}\right)$ was 10,175 \pm 3577 (range: 3940 - 19,500). Anomalies of blood analysis were inflammatory syndrome (100\%), elevation of streptococcal enzymes $(n=27,93 \%)$, and anemia $(n=16,55.2 \%)$. Chest X-ray revealed cardiomegaly $(\mathrm{n}=9,31 \%)$. The EKG reported: sinus rhythm $(\mathrm{n}=29$, $100 \%)$, repolarization abnormalities $(\mathrm{n}=4)$ and first degree heart block $(\mathrm{n}=2)$. In cardiac ultrasound, anomalies were: thickened valve $(\mathrm{n}=13,44.8 \%)$, mitral regurgitation $(\mathrm{n}=13,44.8 \%)$, dilatation of left ventricle $(\mathrm{n}=9,31 \%)$, aortic regurgitation $(n=5,17.2 \%)$, polyvalvulopathy $(n=5)$, and pericardial effusion ( $=3,10.3 \%)$. The nosology of pathology was reported in Table 1 . Treatment used was: corticosteroids $(\mathrm{n}=28,97 \%)$, penicillin $(\mathrm{n}=26,90 \%)$, analgesics $(\mathrm{n}=10$, $34.5 \%)$, diuretics $(n=9,31 \%)$, intravenous rehydration $(n=7,24.1 \%)$, digoxin $(\mathrm{n}=5,17.2 \%)$, enzyme convertor inhibitor $(\mathrm{n}=5,17.2 \%)$, erythromycin $(\mathrm{n}=2)$, transfusion $(\mathrm{n}=2)$ and non-steroid anti-inflammatory (NSAI) $(\mathrm{n}=1)$. The average duration of hospitalization was $22.9 \pm 11.9$ days (range: 5 and 45 days), and prolonged hospitalization was recorded in 15 cases (51.7\%). No death was 
recorded in intra-hospital. Associated disease was malaria $(n=5)$, treated by artemisinin. The associated factors of acute RHD in univariate analysis were female sex, low-income of parents, previous hospitalization, previous ARF, migratory polyarthritis, and prolonged hospitalization (Table 2).

\section{Discussion}

The profile of children admitted for ARF in hospitals is similar to other authors [3] [10]. These are mostly boys, as in screening surveys, carried out in different parts of Africa [10] [11]. Social conditions of these children remain precarious in our study. Indeed, the parents' income level is low [12]. Most of the children admitted, had previously presented ARFs. Despite this, the prevention of penicillin infections is low in our series $20.7 \%$. This denotes the difficulties of access to care for populations in sub-Saharan Africa, but also the lack of knowledge of the disease by medical personnel in our environment [13].

Signs of ARF are diverse and dominated by fever and joint signs that lead parents to consult [1] [3].

Anemia is frequently found in ARF [2] [17]. It is related to inflammation, and its severity can lead to a transfusion as in our study, or to malnutrition because of the poverty of the populations [2] [17].

Cardiac ultrasound has become an indispensable tool in the assessment of ARF [2]. In fact, it makes it possible to detect subclinical lesions and guide subsequent management [3] [12]. The availability of this test remains limited in Africa, justifying screening with cardiac auscultation [11] [12]. This fact explains the lack of knowledge of many cases, which in the long run will be revealed in adulthood [18]. Screening surveys in the Congo used only physical examination, to research a heart murmur [11]. It would be desirable in the future to update the data with an ultrasound survey as currently recommended [2].

In our study, $51.7 \%$ of patients admitted for ARF, presented acute RHD or carditis. It follows of active inflammation of the heart tissues, caused by ARF. Rheumatic carditis can lead to chronic damage that remains after the acute inflammatory episode has resolved [1]. Cardiac surgery is usually deferred until the acute inflammation has subsided so that the repair is technically easier and a

Table 2. Associated factors of acute rheumatic heart disease.

\begin{tabular}{cccccc}
\hline & $\mathrm{n}$ & $\%$ & OR & $95 \% \mathrm{CI}$ & $\mathrm{p}$-value \\
\hline Female sex & 8 & 53.3 & 1.52 & $0.35-6.6$ & 0.57 \\
Low-income & 11 & 73.3 & 1.33 & $0.24-7.4$ & 0.74 \\
Troubled schooling & 2 & 13.3 & 0.66 & $0.1-4.7$ & 0.68 \\
Previous hospitalization & 7 & 46 & 2.7 & $0.58-13$ & 0.201 \\
Previous ARF & 7 & 46 & 2 & $0.44-8.96$ & 0.35 \\
Migratory polyarthritis & 6 & 40 & 1.12 & $0.25-4.9$ & 0.87 \\
Prolonged hospitalization & 9 & 60 & 2.7 & $0.6-12$ & 0.19 \\
\hline
\end{tabular}

ARF: acute rheumatic fever. 
more durable repair can be achieved [1].

Treatment of ARF requires anti-inflammatory treatment with corticosteroids or NSAI [3]. In case of acute RHD, the treatment of heart failure is necessary [3]. Given the long treatment, hospitalizations are prolonged in our context [3]. The treatment of heart valve lesions remains difficult in Africa. In fact, cardiac surgery is of limited access [4] [7], and patients are often supported through medical evacuations abroad, or during NGO missions. In addition, the follow-up of operated patients is difficult, with many patients lost during their follow-up.

The epidemiology of RHD remains unclear in Congo, because all cases are not listed, and the last screening is more than 10 years in Congo [11]. To do this, it is appropriate to advocate with the public authorities, for an update of RHD data [18]. To this must be added the use of echocardiography in screening, to increase sensitivity and specificity in comparison with cardiac auscultation alone [12]. Indeed, the echocardiography allows unmasking the silent RHD [3] [9] [12]. This will build new strategies to eradicate this disease. This also happens, by setting up a cardiac surgery activity permanently. Also, the fight against poverty, remains a major challenge in our country, and the training of qualified medical agent [13].

\section{Limitations of the Study}

This study was conducted in single department of pediatrics at Brazzaville. Which justified a small sample size. It would be desirable to carry out a study in all the departments that hospitalized children at Brazzaville, to have more reliable data. Also, statistics will be improved if a national register of ARF and RHD is set up. As a result, routine tests of ARF in children with fever and arthralgia in the country would be a key element.

\section{Conclusion}

ARF remains prevalent in our countries. Its complications lead to sequelae that are difficult to treat, because of the lack of cardiac surgery centers in many sub-Saharan African countries including Congo. Prevention and effective treatment of pharyngitis should be applied by practitioners.

\section{Conflicts of Interest}

The authors declare no conflicts of interest regarding the publication of this paper.

\section{References}

[1] Carapetis, J.R., Beaton, A., Cunningham, M.W., Guilherme, L., Karthikeyan, G., Mayosi, B.M., et al. (2016) Acute Rheumatic Fever and Rheumatic Heart Disease. Nature Reviews Disease Primers, 2, 15084. https://doi.org/10.1038/nrdp.2015.84

[2] Gewitz, M.H., Baltimore, R.S., Tani, L.Y., Sable, C.A., Shulman, S.T., Carapetis, J., et al. (2015) Revision of the Jones Criteria for the Diagnosis of Acute Rheumatic Fever in the Era of Doppler Echocardiography. A Scientific Statement from the American 
Heart Association. Circulation, 131, 1806-1818. https://doi.org/10.1161/CIR.0000000000000205

[3] Beg, A. and Sadiq, M. (2008) Subclinical Valvulitis in Children with Acute Rheumatic Fever. Pediatric Cardiology, 29, 619-623.

https://doi.org/10.1007/s00246-007-9173-0

[4] Swain, J.D., Mucumbitsi, J., Rusingiza, E., Bolman, R.M. and Binagwaho, A. (2014) Cardiac Surgery for Advanced Rheumatic Heart Disease in Rwanda. The Lancet Global Health, 2, e141-e142. https://doi.org/10.1016/S2214-109X(14)70022-1

[5] Yacoub, M., Mayosi, B., El Guindy, A., Carpentier, A. and Yusuf, S. (2017) Eliminating Acute Rheumatic Fever and Rheumatic Heart Disease. The Lancet, 390, 212-213. https://doi.org/10.1016/S0140-6736(17)31608-2

[6] Abdullahi, L.H., Smit, I., Engel, M.E., Watkins, D.A. and Zühlke, L.J. (2019) Task Sharing in the Diagnosis, Prevention, and Management of Rheumatic Heart Disease. A Systematic Review. Global Heart, 14, 259-264. https://doi.org/10.1016/j.gheart.2019.04.002

[7] Zilla, P., Bolman, R.M., Yacoub, M.H., Beyersdorf, F., Silwa, K., Zühlke, L., et al. (2018) The Cape Town Declaration on Access to Cardiac Surgery in the Developing World. Cardiovascular Journal of Africa, 29, 256-259. https://doi.org/10.5830/CVJA-2018-046

[8] Mayosi, B.M. (2016) 2016 National Rheumatic Fever Week: The Status of Rheumatic Heart Disease in South Africa. South African Medical Journal, 106, 740-741. https://doi.org/10.7196/SAMJ.2016.v106i8.11253

[9] Mayosi, B.M., Gamra, H., Dangou, J.M. and Kasonde, J. (2014) The Challenge of Silent Rheumatic Heart Disease. The Lancet Global Health, 2, e677-e678. https://doi.org/10.1016/S2214-109X(14)70331-6

[10] O’Meara, W.P., Mott, J.A., Wamburu, K., Fields, B., Armstrong, J., Taylor, S.M., MacIntyre, C., et al. (2015) Etiology of Pediatric Fever in Western Kenya: A Case-Control Study of Falciparum Malaria, Respiratory Viruses, and Streptococcal Pharyngitis. American Journal Tropical Medicine Hygiene, 92, 1030-1037. https://doi.org/10.4269/ajtmh.14-0560

[11] Kimbally Kaky, G., Gombet, T., Voumbo, Y., Ikama Meo, S., Ellenga Mbolla, B., Mbika Cardorelle, A., et al. (2008) Rheumatic Heart Disease in Schoolchildren in Brazzaville. Medecine Tropicale, 68, 603-605.

[12] Marijon, E., Ou, P., Celermajer, D.S., Ferreira, B., Mocumbi, A.O., Jani, D., et al. (2007) Prevalence of Rheumatic Heart Diseases Detected by Echocardiographic Screening. New England Journal of Medicine, 357, 470-476. https://doi.org/10.1056/NEJMoa065085

[13] Nkoke, C., Luchuo, E.B., Jingi, A.M., Makoge, C., Hamadou, B. and Dzudie, A. (2018) Rheumatic Heart Disease Awareness in the South West Region of Cameroon: A Hospital Based Survey in a Sub-Saharan African Setting. PLoS ONE, 13, e0203864. https://doi.org/10.1371/journal.pone.0203864

[14] Murala, J.S.K., Karl, T.R. and Pezzella, A.T. (2019) Pediatric Cardiac Surgery in Low- and Middle-Income Countries: Present Status and Need for a Paradigm Shift. Frontiers in Pediatrics, 7, 214. https://doi.org/10.3389/fped.2019.00214

[15] Republic of the Congo (2017) Report on the Analysis of Poverty in Congo. Education, Employment and Social Protection for Sustainable Poverty Reduction. World Bank Group.

http://documents.worldbank.org/curated/en/359991503510903731/pdf/114706-FRE 
NCH-v2-Republic-of-Congo-FRE-7-17-17-M3.pdf

[16] WHO (2011) Haemoglobin Concentration for the Diagnosis of Anaemia and the Assessment of Severity. Vitamin and Mineral Nutrition Information System. World Health Organization, Geneva.

http://www.who.int/vmnis/indicators/haemoglobin.pdf

[17] Rasa, M., Garcia, A., Yamaga, K., Nguyen, L., Hamamura, F.D., Tam, E., et al. (2018) Hematologic and Hepatic Anomalies in Pediatric Acute Rheumatic Fever. Annals of Pediatric Research, 2, 1016.

[18] Mayosi, B.M., Gamra, H., Dangou, J.M. and Kasonde, J. (2014) Rheumatic Heart Disease in Africa: The Mosi-O-Tinya Call to Action. The Lancet Global Health, 2, e438-e439. https://doi.org/10.1016/S2214-109X(14)70234-7 